\title{
Free electron concentration dependent sub-bandgap optical absorption characterization of bulk GaN crystals
}

\author{
S. Pimputkar ${ }^{1, a)}$, S. Suihkonen ${ }^{2}$, M. Imade ${ }^{3}$, Y. Mori ${ }^{3}$, J.S. Speck ${ }^{1}$, S. Nakamura ${ }^{1}$ \\ ${ }^{1}$ Materials Department, Solid State Lighting and Energy Electronics Center, University of California, Santa \\ Barbara, CA 93106-5050, USA \\ ${ }^{2}$ Department of Micro- and Nanosciences, Aalto University, Espoo, Finland \\ ${ }^{3}$ Division of Electrical, Electronic and Information Engineering, Graduate School of Engineering, Osaka \\ University, Suita, Osaka 565-0871, Japan \\ a) Electronic mail: siddha@engr.ucsb.edu
}

Optical transmission measurements were performed on high quality bulk gallium nitride (GaN) crystals grown by sodium flux, hydride vapor phase epitaxy, and the ammonothermal method with varying free electron concentrations ranging from $4 \times 10^{16} \mathrm{~cm}^{-3}$ to $9 \times 10^{18} \mathrm{~cm}^{-3}$. The quality of the crystals was analyzed by $\mathrm{X}$ ray diffraction, threading dislocation density determination, impurity concentrations, and Hall mobility measurements. The sub-bandgap absorption coefficient and index of refraction was determined based on illumination wavelengths ranging from $360 \mathrm{~nm}$ to $800 \mathrm{~nm}$. Phonon-assisted free carrier absorption was determined to be the dominant absorption mechanism above approximately $0.1 \mathrm{~cm}^{-1}$. The absorption coefficient at $450 \mathrm{~nm}$ varied linearly from $0.1 \mathrm{~cm}^{-1}$ to $5 \mathrm{~cm}^{-1}$ for free electron concentrations ranging from $1 \times 10^{17} \mathrm{~cm}^{-3}$ to $9 \times 10^{18} \mathrm{~cm}^{-3}$. The ammonothermal GaN samples exhibited a strong defect related onset of absorption above $2.9 \mathrm{eV}$ which can be explained by the presence of appreciable hydrogenated gallium vacancies having defect states close to the 
valance band within the electric bandgap of GaN. The presence of hydrogenated gallium vacancies was experimentally confirmed by Fourier transform infrared absorbance measurements and double hydrogenated gallium vacancy defect are speculated to be prominent in ammonothermal GaN.

Keywords: A2. Bulk GaN crystals; B1. Gallium Nitride; A1. Sub-bandgap optical absorption; A1. Free electron concentration; A1. Gallium vacancy

\section{Introduction}

The wide bandgap semiconductor gallium nitride $(\mathrm{GaN})$ is used for numerous electronic applications, though notably for optoelectronic devices such as visible light emitting diodes (LEDs) and lasers operating at wavelengths of $450 \mathrm{~nm}$ or longer. Improvements to device performance can be made by reducing defects in the epitaxial layers by growing on high quality, native substrates. Understanding absorption losses of sub-bandgap visible light passing through high quality GaN substrates is important to optimize the optoelectronic structure.

In addition to its importance for optoelectronic devices, sub-bandgap absorption is a sensitive indicator of semiconductor material quality and free electron concentration. A basic understanding of the sub-bandgap absorption behavior of $\mathrm{GaN}$ for wavelengths between $360 \mathrm{~nm}$ and $800 \mathrm{~nm}$ can be gleaned from the few existing reports which performed optical absorption measurements on epitaxial GaN films grown on sapphire substrates using photothermal deflection spectroscopy (PDS) $)^{1,2,3,4}$ and optical transmission method ${ }^{5}$, along with a few isolated measurements using optical transmission measurements on bulk GaN crystals grown by the 
ammonothermal method $^{6}$ or hydride vapor phase epitaxy (HVPE) ${ }^{7}$. No report was found which systematically investigated the dependence of sub-bandgap absorption of high quality, bulk GaN crystals on free electron concentration (FEC).

In this paper, we report on the variation of the absorption coefficient and refractive index between $360 \mathrm{~nm}$ and $800 \mathrm{~nm}$ for $n$-type bulk GaN crystals grown by the ammonothermal method, HVPE and sodium flux (Na-flux) method using the optical transmission method. Their dependence on FEC varying between $4 \times 10^{16} \mathrm{~cm}^{-3}$ to $9 \times 10^{18} \mathrm{~cm}^{-3}$ and material quality is analyzed. Hall mobility was determined as a function of FEC on the bulk crystals and compared to anticipated values given existing experimental and computational data.

\section{Experimental procedure}

Five $c$-plane oriented, oxygen doped HVPE bulk GaN crystals were grown by Mitsubishi Chemical Corporation (MCC) ${ }^{8}$.

Ammonothermal bulk GaN was grown at UCSB in a silver capsule system on a HVPE bulk GaN crystal grown by MCC. ${ }^{9}$ Use of a silver capsule system reduced transition metal impurities coming from the autoclave walls in the GaN crystals by one to two orders of magnitude, as verified by manganese concentrations being below detection limit (without silver capsule system [Mn] low $10^{18} \mathrm{~cm}^{-3}$ ). Sodium was intentionally added to the ammonothermal growth environment to enhance solubility of GaN into solution. The resulting $4 \mathrm{~mm}$ thick boule was cut using a wire saw to remove the seed crystal yielding two $c$-plane oriented crystals, one from the Ga-face growth along [0001] and one from the N-face growth along [000-1]. 
Na-flux GaN was grown at Osaka University ${ }^{10}$ on a $c$-plane oriented sapphire substrate which was removed. Despite the use of $\mathrm{Na}$ in the flux material, it did not detectibly incorporate into the crystal, as verified by sodium impurities levels being below detection limit.

All crystals part of this study were planarized to ensure the optically transversed crystal surfaces were parallel to each other. The HVPE and Na-Flux GaN crystals were polished on one side to an epitaxial smooth finish using chemical-mechanical polish (CMP), while the back side and both sides of the ammonothermal GaN crystals were polished to be optically smooth without any observable scratches using differential interference contrast microscopy (DICM), secondary electron microscopy (SEM), or cathodoluminescence (CL) measurements. The choice of $c$-plane crystals was deliberate to minimize anisotropic effects resulting from the birefringent wurtzite GaN crystals (space group $\mathrm{P}_{3} \mathrm{mc}$ ).

Optical absorption measurements were performed at room temperature (RT) by independently determining the reflectance $R_{\text {meas }}\left(12.5^{\circ}\right.$ angle of incidence) and transmittance $T_{\text {meas }}$ (normal incidence) of each sample using a Cary 500 UV-Vis-NIR spectrophotometer for unpolarized light with wavelengths ranging between $360 \mathrm{~nm}$ and $800 \mathrm{~nm}$. The absorption coefficient, $\alpha$, and reflection coefficient, $R$, were determined by solving two coupled equations ${ }^{11}$ which account for multiple internal reflections within the sample, $T_{\text {meas }}=\left((1-R)^{2} e^{-\alpha t}\right) /\left(1-R^{2} e^{-2 \alpha t}\right)$ and $R_{\text {meas }}=R+R(1-R)^{2} e^{-2 \alpha t}$, wherein $t$ is the sample thickness. Given the accuracy of the experimental setup, only the reflection from the first traversed interface (air to GaN) and the transmitted portion of the attenuated beam which reflected off the second interface ( $\mathrm{GaN}$ to air) were included in the calculations (see also insert in FIG. 6). The refractive index $n$ was determined assuming normal incidence and $R=(n-1)^{2} /(n+1)^{2}$. 
Carrier type, concentration and Hall mobility were determined at RT using a Lakeshore 7504 Hall effect system. Crystal quality was characterized by high resolution x-ray diffraction (HRXRD) and measuring the full width at half maximum (FWHM) of the omega rocking curve $(\omega-\mathrm{XRC})$ for the on-axis (0002) and off-axis (11-22) Bragg plans using a nominal spot size of 10 $\mathrm{mm} \times 1 \mathrm{~mm}$. Impurity concentrations for the ammonothermal samples were measured using secondary ion mass spectrometry (SIMS) using a Physical Electronics 6650 Dynamic SIMS. Optical absorbance measurements between $3000 \mathrm{~cm}^{-1}$ and $3500 \mathrm{~cm}^{-1}$ were performed using Fourier transform infrared spectroscopy (FTIR) using a Nicolet Magna 850 FTIR spectrometer. Threading dislocation densities (TDD) were determined using CL measurements. In all presented figures, all samples are color coded and corresponding colors correspond to the same sample.

\section{Results and Discussion}

Table I summarizes the values determined for the FWHM of the $\omega$-XRC measured using HRXRD, TDD measured using CL and impurity concentrations measured using SIMS for the investigated samples. FIG. 1 summarizes measured FEC and Hall mobility values for all eight investigated samples and compares them to two models providing an approximate upper bound ${ }^{12}$

and typical values based on a representative fit $^{13}$ through numerous experimental data points collected from thin films since 1997.

TABLE I. Summary of various crystal quality metrics for investigated samples grown using different growth techniques. The Na-Flux and ammonothermal GaN crystals were unintentionally doped with oxygen, whereas HVPE GaN was intentionally doped with oxygen. All other impurities are unintentional. 


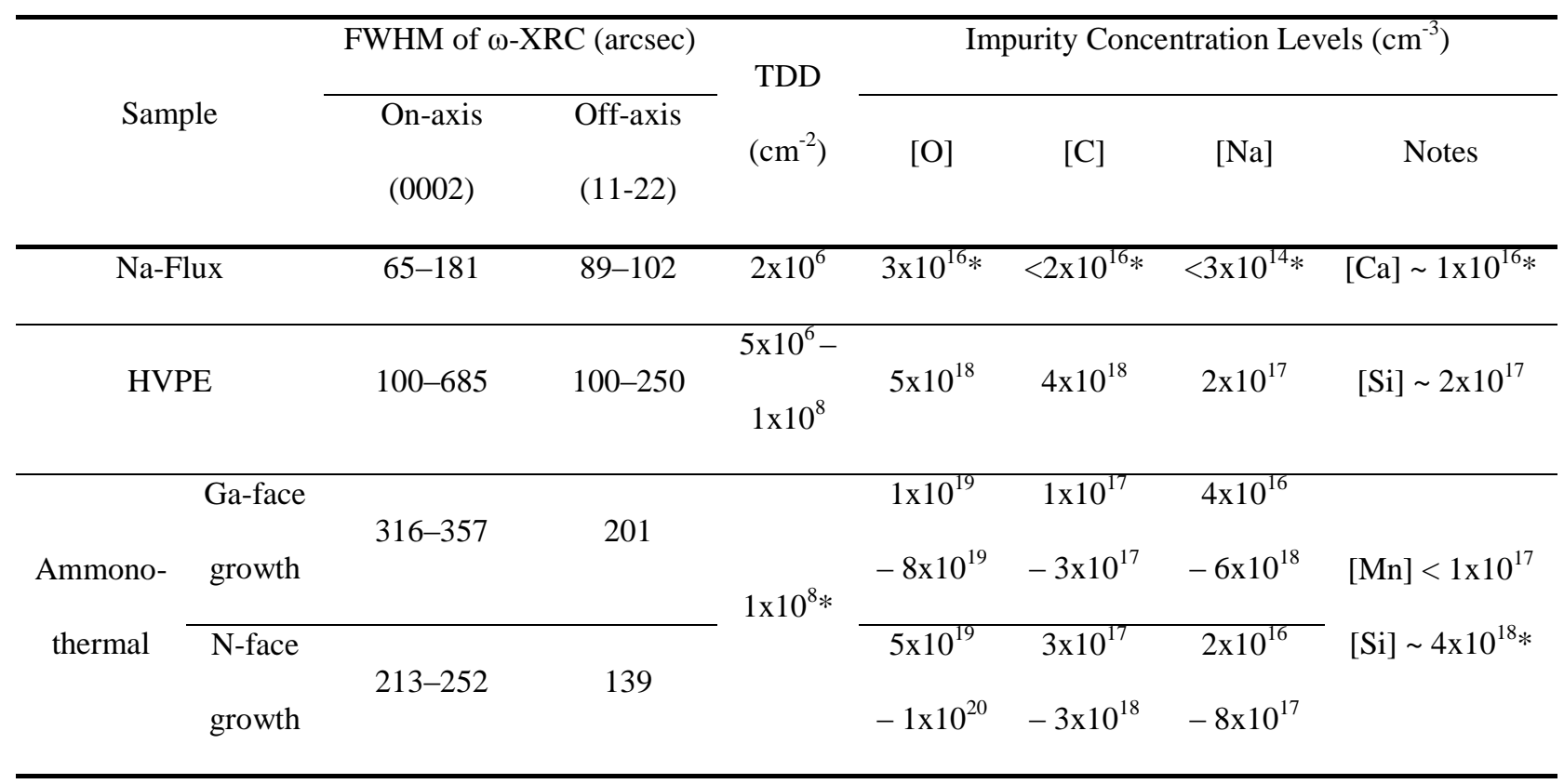

Notes: * indicates typical values, not explicitly evaluated for sample under investigation. Impurities: Na-flux values from Ref [14], ammonothermal GaN from Ref [9], only one HVPE sample was analyzed. TDD for ammonothermal GaN based on HVPE seed TDD density. 


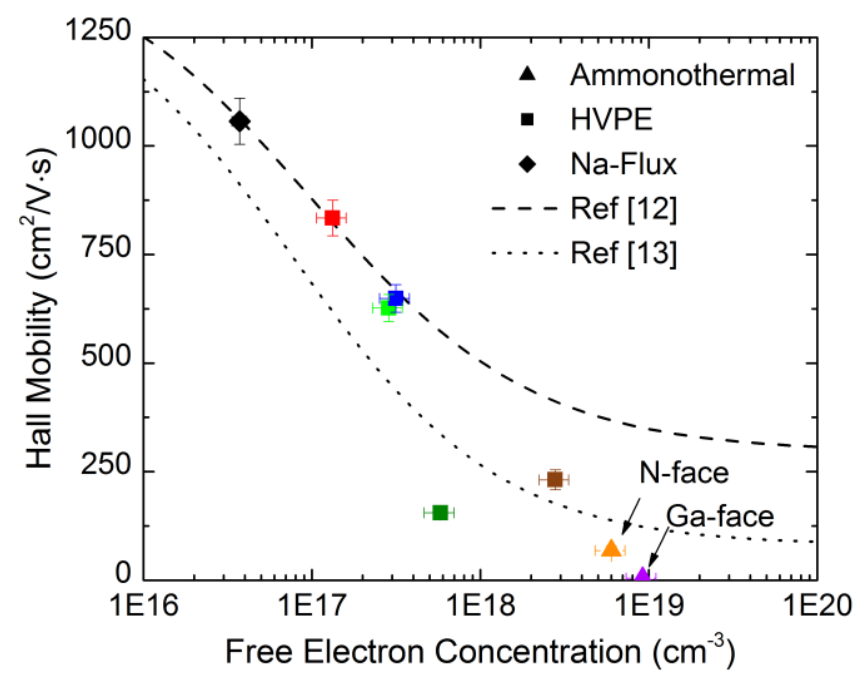

FIG. 1. Hall mobility as a function of free electron concentrations measured at RT for all eight samples part of this study. Growth technique used to grow each respective bulk GaN sample is indicated by its symbol. Comparison is made to two models: Monte Carlo low-field simulations (Ref 12) and a representative fit through numerous experimentally determined mobility data (Ref 13)

All samples have comparable crystal quality, with the Na-flux yielding the highest purity, lowest TDD and lowest $\mathrm{x}$-ray rocking curve width. Its Hall mobility of $1057 \pm 53 \mathrm{~cm}^{2} / \mathrm{V} \cdot \mathrm{s}$ is near the highest mobility recorded to date, $1265 \mathrm{~cm}^{2} / \mathrm{V} \cdot \mathrm{s}$, for GaN with similar FEC and TDD. ${ }^{15}$ The HVPE samples are of typical commercial quality and have [C] and [Na] comparable to those of the ammonothermal GaN. Their mobility is high, with the exception of the two highest FEC samples. The sample with $5.8 \times 10^{17} \mathrm{~cm}^{-2} \mathrm{FEC}$ has an anomalously low Hall mobility, presumably due to unknown defects within the crystal, while the highest FEC sample was grown using lateral epitaxy overgrowth (LEO) methods, providing additional scattering interfaces in the coalescence regions. The Ga-face ammonothermal sample is inferior to the $\mathrm{N}$-face growth due to nucleation 
challenges resulting in more pronounced columnar growth, as indicated by the higher on- and off-axis x-ray rocking curve width and a poor mobility of $5 \mathrm{~cm}^{2} / \mathrm{V} \cdot \mathrm{s}$, as compared to $69 \pm 10$ $\mathrm{cm}^{2} / \mathrm{V} \cdot \mathrm{s}$ for the $\mathrm{N}$-face growth. The samples exhibited marked variations in impurity incorporation between wing and seeded growth regions. The optically investigated region, though, was more uniform and exhibited a smaller spread in $[\mathrm{Na}]$ variation $\left(\sim \operatorname{mid} 10^{17} \mathrm{~cm}^{-3}\right)$ and was comparable to the HVPE samples.

Sub-bandgap optical absorption measurements were performed and are summarized in FIG. 3. The trace is characterized by a minimum in absorption for photon energies between $1.8-2.1 \mathrm{eV}$ and a pronounced onset of absorption near $2.9 \mathrm{eV}$ for the ammonothermal samples and $3.2 \mathrm{eV}$ for all other samples. A clear, linear increase in absorption coefficient at $450 \mathrm{~nm}$ is found with increasing FEC as is also shown in FIG. 4 which compares well with an existing study on the increase in absorption coefficient at $450 \mathrm{~nm}$ with increasing oxygen doping for ammonothermal GaN. $^{16}$

While direct free electron absorption should be insignificant in $n$-type GaN due to dipole forbidden transitions of free electrons to the second conduction band situated $2.5 \mathrm{eV}$ above the conduction band minimum and a lack of hole states available in the relevant energy ranges, it is possible that an indirect, phonon-assisted process is occurring and significantly contributing to the optical losses. For electrons residing in the conduction band of $\mathrm{GaN}$, this would require the simultaneous absorption of a photon and a phonon of the proper energy to cause an intraband transition (see also FIG. 2). Holes residing in the valence band can undergo both an indirect intra- or interband transition, though these contributions will be small for the investigated $n$-type GaN samples. In FIG. 3 and FIG. 4, the dashed lines represent the anticipated contribution to the 
optical absorption coefficient from phonon-assisted free carrier absorption calculated from firstprinciples $^{17,18}$ for the indicated FECs at RT.

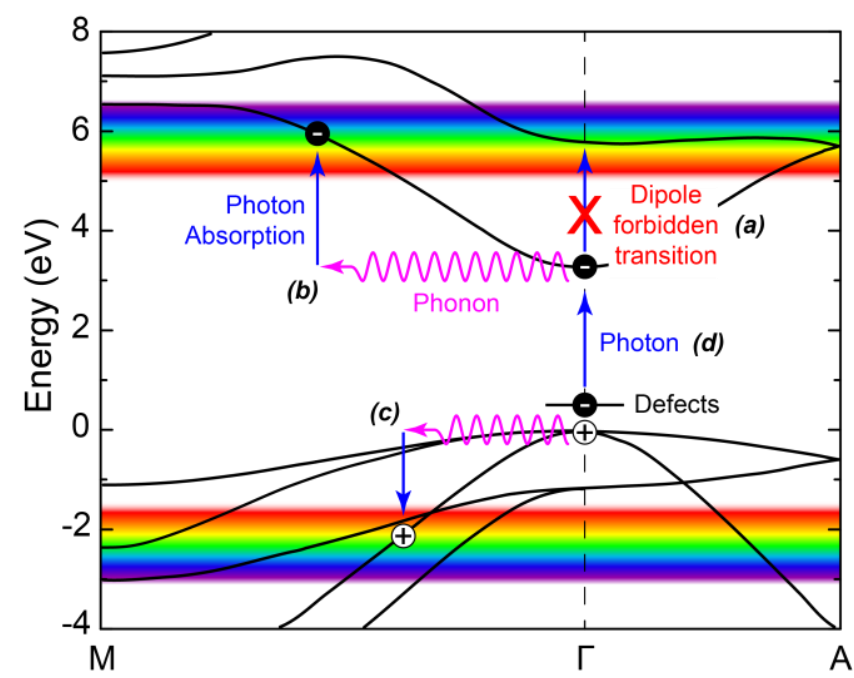

FIG. 2. GaN band structure with overlaid possible absorption mechanisms for electrons and holes: (a) dipole forbidden direct absorption from the conduction band minimum to the second conduction band, phonon-assisted (b) intraband and (c) interband absorption, (d) direct absorption from defect state. Colors correspond to energy levels to which an electron from the conduction band minimum or a hole from the valence band maximum would be elevated to after absorbing a photon with an energy corresponding to the displayed color.

Excellent agreement is provided for all but the lowest FEC samples, suggesting phonon-assisted free carrier absorption is the dominant absorption loss mechanism above FEC of $1 \times 10^{17} \mathrm{~cm}^{-2}$. The Na-flux sample with FEC of $3.7 \times 10^{16} \mathrm{~cm}^{-2}$ appears to be more absorbing than anticipated, indicating that other defect related absorption processes are dominant below an FEC of 1 $10^{17}$ $\mathrm{cm}^{-2}$. 
The HVPE samples with FEC ranging from $1.3 \times 10^{17}$ to $2.8 \times 10^{18}$ show an excellent fit with calculations. Only the $5.8 \times 10^{17} \mathrm{~cm}^{-2}$ FEC HVPE sample absorption is increased around $2.1 \mathrm{eV}$ suggesting defects, consistent with the low mobility of the sample. Close to the absorption edge, from 3.0 to $3.2 \mathrm{eV}$, an absorption tail is found in all Na-flux and HVPE grown samples yielding higher absorption than expected just from free carriers. This is indicative of defects, or possibly an Urbach tail, as would be anticipated given finite TDDs.

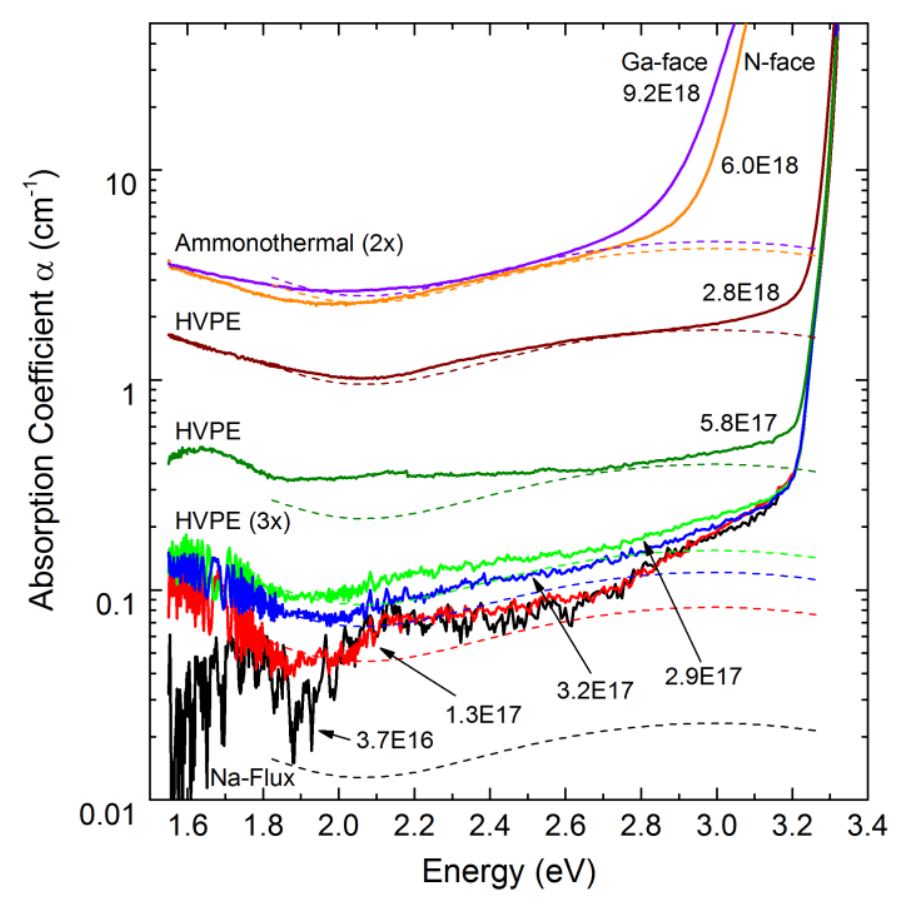

\begin{tabular}{|c|c|c|c|}
\hline \multirow{2}{*}{$\begin{array}{l}\text { Growth } \\
\text { Technique }\end{array}$} & \multicolumn{2}{|c|}{ Free Electron Concentration $\left(\mathrm{cm}^{-3}\right)$} & \multirow{2}{*}{$\begin{array}{l}\text { Thickness } \\
\text { Crystal }(\mu \mathrm{m})\end{array}$} \\
\hline & Experiment & Theory & \\
\hline Na-Flux & $\longrightarrow(3.7 \pm 0.4) \mathrm{E} 16$ & $---3.7 E 16$ & 490 \\
\hline HVPE & $\begin{array}{r}-(1.3 \pm 0.3) \mathrm{E} 17 \\
-(2.9 \pm 0.6) \mathrm{E} 17 \\
-(3.2 \pm 0.6) \mathrm{E} 17 \\
-(5.8 \pm 1.2) \mathrm{E} 17 \\
-(2.8 \pm 0.6) \mathrm{E} 18\end{array}$ & $\begin{array}{ll}-\cdots & 1.3 \mathrm{E} 17 \\
-\cdots & 2.5 \mathrm{E} 17 \\
--- & 2.0 \mathrm{E} 17 \\
--- & 6.4 \mathrm{E} 17 \\
--- & 2.8 \mathrm{E} 18\end{array}$ & $\begin{array}{l}334 \\
337 \\
339 \\
350 \\
329\end{array}$ \\
\hline $\begin{array}{l}\text { Ammono- } \\
\text { thermal }\end{array}$ & $\begin{array}{r}-(6.0 \pm 1.2) \mathrm{E} 18 \\
-(9.2 \pm 1.8) \mathrm{E} 18\end{array}$ & $\begin{array}{ll}\cdots & 6.8 \mathrm{E} 18 \\
\cdots & 7.3 \mathrm{E} 18\end{array}$ & $\begin{array}{l}630 \\
636\end{array}$ \\
\hline
\end{tabular}

FIG. 3. Experimentally determined sub-bandgap optical absorption coefficient traces for bulk GaN samples grown using different growth techniques as a function of free carrier concentration 
at RT. Sample thickness is indicated in the legend. Dashed lines represent computationally anticipated values for phonon-assisted free carrier absorption based on first-principle calculations (Ref. 17,18). The 'Theory' column in the figure provides electron densities used for each calculated curve for each respective crystal.

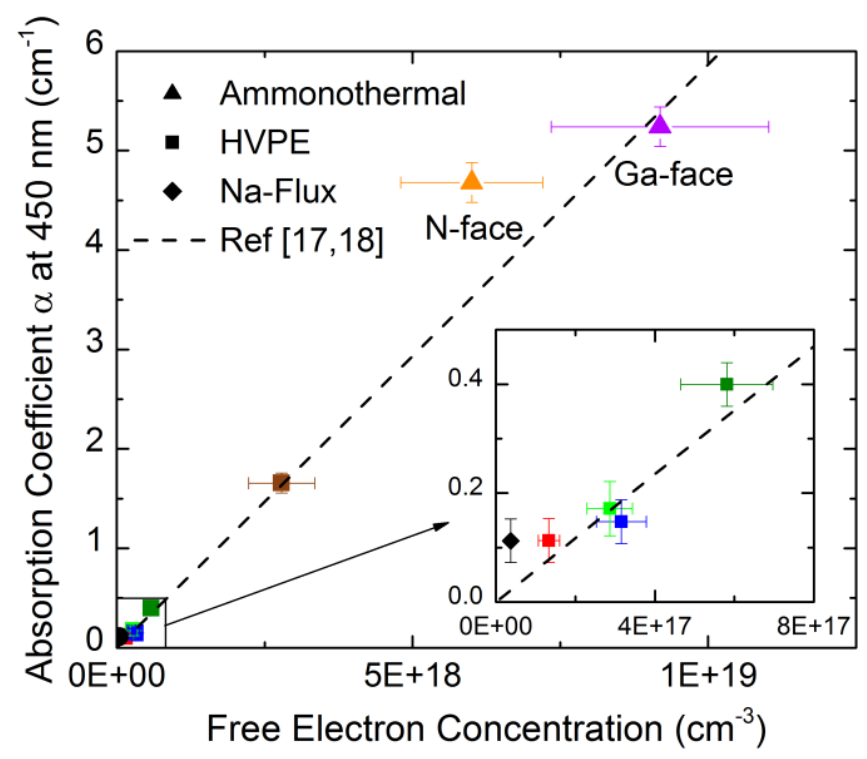

FIG. 4. Measured absorption coefficient at a wavelength of $450 \mathrm{~nm}$ as a function of free carrier concentration in the bulk GaN sample. Insert provides close-up of the lower concentration samples. The dashed line is the anticipated contribution to the absorption coefficient from phonon-assisted free carrier absorption (Ref 17,18).

Both ammonothermal samples show a strong increase in absorption above $2.9 \mathrm{eV}$, most likely due to defects or their non-uniform distribution. As the FEC and measured impurities of the ammonothermal and HVPE grown samples are comparable, the most likely source for the strong onset of absorption is a defect related state in the ammonothermal samples. A possible 
explanation for the observed shift in absorption edge for the ammonothermal $\mathrm{GaN}$ can be found by analyzing the refractive index traces (FIG. 5), measured reflectance in proximity of the band edge (FIG. 6), and performing FTIR absorbance measurements.

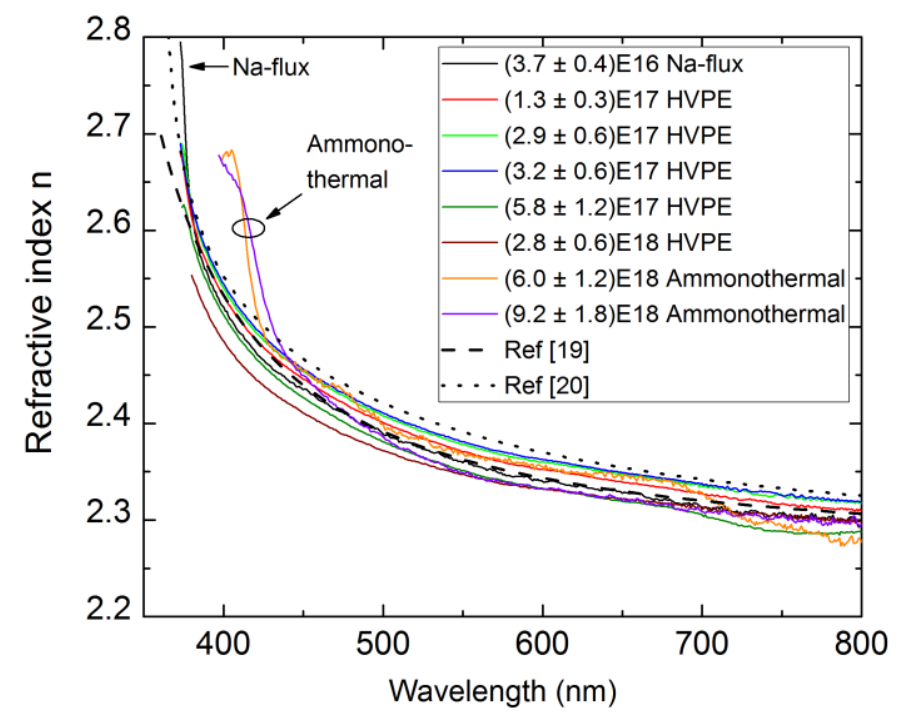

FIG. 5. Dependence of the refractive index, $n$, from experimentally determined reflection coefficient, $R$, on wavelength and free carrier concentration at room temperature. The angle of incidence of unpolarized light for reflectance measurements was $12.5^{\circ}$. Comparison to measurements performed on thin films over the full spectrum are included as dashed (Ref 19) and dotted (Ref 20) lines. 


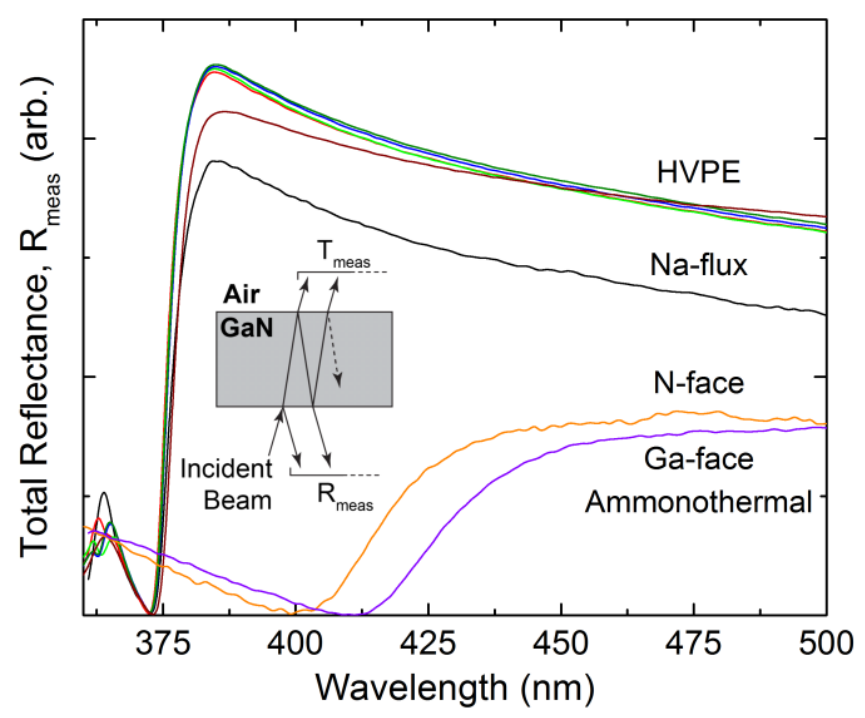

FIG. 6. Measured reflectance, $R_{\text {meas }}$, for bulk GaN samples as a function of incident light energy highlighting their behavior near the band edge.

The measured refractive index is compared to a one-Sellmeier-term fit ${ }^{19}$ and a two-Sellmeierterm fit for the ordinary refractive index $\left(n_{O}\right){ }^{20}$ with good agreement within accuracy of the experimental setup providing confidence in the accuracy of the performed absorption measurements. The reflectance measurements yielded a minimum at $373.2 \mathrm{~nm}$ for the Na-flux, between $372.9-373.6 \mathrm{~nm}$ for the HVPE, $399 \mathrm{~nm}$ for the $\mathrm{N}$-face and $411 \mathrm{~nm}$ for the Ga-face ammonothermal GaN. If the measured traces are shifted to shorter wavelengths by the difference in reflectance minimum position, the ammonothermal $\mathrm{GaN}$ behaves similar to the other $\mathrm{GaN}$ samples with regards to the refractive index and reflectance measurements. This suggests defect states close to the valance band. 


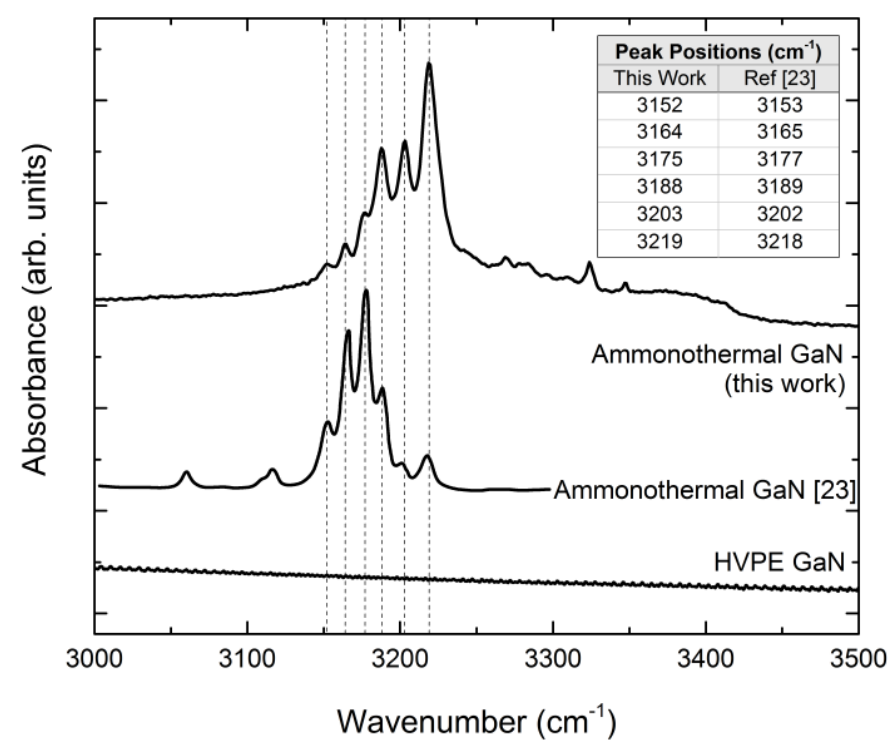

FIG. 7. Fourier transform infrared (FTIR) absorbance measurement on as grown Ga-face grown ammonothermal sample (this work) compared to literature data for another ammonothermal GaN sample (Ref 23) and a characteristic hydride vapor phase epitaxy (HVPE) GaN sample. Peaks are in the region of calculated hydrogen vibration frequencies associated with hydrogenated gallium vacancy species: $2986-3650 \mathrm{~cm}^{-1}$ (Ref 22).

FTIR absorbance analysis of the Ga-face ammonothermal GaN exhibited pronounced absorption peaks at various frequencies between $3150-3220 \mathrm{~cm}^{-1}$ (see FIG. 7), while no absorbance was found in the same range for three analyzed HVPE samples of comparable crystal quality not part of this study with FECs ranging between $1.3 \times 10^{17} \mathrm{~cm}^{-3}$ and $6.5 \times 10^{17} \mathrm{~cm}^{-3}$. Absorption in this frequency range can be attributed to gallium vacancies hydrogenated with a varying number of hydrogen atoms $\left(\mathrm{V}_{\mathrm{Ga}} \mathrm{H}^{2-}, \mathrm{V}_{\mathrm{Ga}} \mathrm{H}_{2}^{-}, \mathrm{V}_{\mathrm{Ga}} \mathrm{H}_{3}{ }^{0}, \mathrm{~V}_{\mathrm{Ga}} \mathrm{H}_{4}{ }^{+}\right)^{21,22}$, though absorption from hydrogenated gallium vacancy oxygen complexes $\left(\mathrm{V}_{\mathrm{Ga}} \mathrm{O}_{\mathrm{N}}\right)$ cannot be ruled out. The determined absorbance peak positions were comparable to those found for other ammonothermal samples ${ }^{23,24}$, though their differing intensity profiles suggests the presence of at least two different types of 
hydrogenated vacancy defects. Positron annihilation of ammonothermal GaN provides additional evidence of the presence of hydrogenated gallium vacancies in ammonothermal GaN. ${ }^{24}$ Given comparable impurity concentrations, excluding [O], between the HVPE and ammonothermal GaN samples, it is therefore suggested that hydrogenated gallium vacancies are the primary cause of strong defect related absorption at 2.8-3.3 eV. High levels of oxygen in the samples may form an impurity band which merges with the conduction band. ${ }^{25}$ However, the O impurity band is unlikely to cause the observed absorption at $2.9 \mathrm{eV}$ in the ammonothermal samples given the isolated oxygen defect level is only $\sim 0.08 \mathrm{eV}$ below the conduction band.

Deep level optical spectroscopy and deep level transient spectroscopy performed on hydrogenated metal organic chemical vapor deposition $\mathrm{GaN}$ yielded observed defect energy levels of $2.64,2.74$, and $2.80 \mathrm{eV}$ below the conduction band with tentative assignments to $\mathrm{V}_{\mathrm{Ga}}{ }^{3-}$, $\mathrm{V}_{\mathrm{Ga}} \mathrm{H}^{2-}$, and $\mathrm{V}_{\mathrm{Ga}} \mathrm{H}_{2}{ }^{-}$, respectively. ${ }^{26}$ First principle calculations suggest defect energy levels of 2.62, 2.68, 2.81, and $3.28 \mathrm{eV}$ below the conduction band for $\mathrm{V}_{\mathrm{Ga}}{ }^{3-}, \mathrm{V}_{\mathrm{Ga}} \mathrm{H}^{2-}, \mathrm{V}_{\mathrm{Ga}} \mathrm{H}_{2}{ }^{-}$, and $\mathrm{V}_{\mathrm{Ga}} \mathrm{H}_{3}{ }^{0}$, respectively. ${ }^{27}$ This would suggest double hydrogenated gallium vacancy as the most likely point defect present with appreciable concentration in ammonothermal samples.

\section{Conclusions}

In summary, free carrier dependent sub-bandgap optical absorption of bulk GaN crystals grown by Na-Flux, HVPE, and ammonothermal were characterized. The sub-bandgap absorption appears to be dominated by phonon-assisted free carrier absorption and a linear relationship between FEC ranging from $1 \times 10^{17} \mathrm{~cm}^{-3}$ to $9 \times 10^{18} \mathrm{~cm}^{-3}$ on the absorption coefficient ranging from $0.11 \mathrm{~cm}^{-1}$ to $5.2 \mathrm{~cm}^{-1}$ is found. The ammonothermal samples, while comparable in impurity concentrations, TDD, and crystal quality, exhibited strong defect related absorption above 2.9 
$\mathrm{eV}$, presumably due to a high concentration of double hydrogenated gallium vacancies which have defect states close to the valence band in the bandgap.

\section{Acknowledgments}

The first author wishes to acknowledge fruitful discussions with Prof. Chris Van de Walle and the generous support by the National Science Foundation Graduate Research Fellowship (NSF-GRFP) under Grant No. DGE-0707460 and by the U.S. Department of Homeland Security (DHS) Graduate Student Fellowship Program under DOE contract number DE-AC05-06OR2310. The authors acknowledge the support from the Solid State Lighting and Energy Electronics Center at University of California, Santa Barbara the MRL Central Facilities, which are supported by the MRSEC Program of the NSF under Award No. DMR 1121053; a member of the NSF-funded Materials Research Facilities Network (www.mrfn.org). Great gratitude is extended to Takatori Corporation for their generous donation of the wire saw used to cut the GaN samples. All opinions expressed in this paper are the author's and do not necessarily reflect the policies and views of NSF, DHS, DOE, or ORAU/ORISE.

${ }^{1}$ O. Ambacher, W. Rieger, P. Ansmann, H. Angerer, T.D. Moustakas, and M. Stutzmann, Solid State Communications 97, 365 (1996).

${ }^{2}$ W. Rieger, R. Dimitrov, D. Brunner, E. Rohrer, O. Ambacher, and M. Stutzmann, Phys. Rev. B 54, 17596 (1996).

${ }^{3}$ G. Bentoumi, A. Deneuville, B. Beaumont, and P. Gibart, Materials Science and Engineering: B 50, 142 (1997).

${ }^{4}$ N. Lobo, A. Kadir, M.R. Laskar, A.P. Shah, M.R. Gokhale, A.A. Rahman, B.M. Arora, K.L. Narasimhan, and A. Bhattacharya, J. Cryst. Growth 310, 4747 (2008). 
${ }^{5}$ G. Yu, G. Wang, H. Ishikawa, M. Umeno, T. Soga, T. Egawa, J. Watanabe, and T. Jimbo, Appl. Phys. Lett. 70, 3209 (1997).

${ }^{6}$ W. Jiang, D. Ehrentraut, B.C. Downey, D.S. Kamber, R.T. Pakalapati, H.D. Yoo, and M.P. D'Evelyn, J. Cryst. Growth 403, 18 (2014).

${ }^{7}$ T. Sochacki, Z. Bryan, M. Amilusik, R. Collazo, B.L. Lucznik, J.L. Weyher, G. Nowak, B. Sadovyi, G. Kamler, R. Kucharski, M. Zając, R.M. Doradziński, R.T. Dwiliński, I. Grzegory, M. Bockowski, and Z. Sitar, Appl. Phys. Express 6, 075504 (2013).

${ }^{8}$ K. Fujito, S. Kubo, H. Nagaoka, T. Mochizuki, H. Namita, and S. Nagao, J. Cryst. Growth 311, 3011 (2009).

${ }^{9}$ S. Pimputkar, S. Kawabata, J.S. Speck, and S. Nakamura, J. Cryst. Growth 403, 7 (2014).

${ }^{10}$ M. Imanishi, K. Murakami, H. Imabayashi, H. Takazawa, Y. Todoroki, D. Matsuo, M. Maruyama, M. Imade, M. Yoshimura, and Y. Mori, Appl. Phys. Express 5, 095501 (2012).

11 J.I. Pankove, Optical Processes in Semiconductors, (Dover, 1975), pp. 87—95

${ }^{12}$ M. Farahmand, C. Garetto, E. Bellotti, K.F. Brennan, M. Goano, E. Ghillino, G. Ghione, J.D. Albrecht, and P.P. Ruden, IEEE Trans. Electron Devices 48, 535 (2001).

${ }^{13}$ F. Schwierz, Solid-State Electronics 49, 889 (2005).

${ }^{14}$ Y. Mori, M. Imade, M. Maruyama, and M. Yoshimura, ECS J. Solid State Sci. Technol. 2, N3068 (2013).

${ }^{15}$ E.C.H. Kyle, S.W. Kaun, P.G. Burke, F. Wu, Y.-R. Wu, and J.S. Speck, J. Appl. Phys. 115, 193702 (2014).

${ }^{16}$ E.R. Letts, T. Hashimoto, S. Hoff, D. Key, K. Male, and M. Michaels, J. Cryst. Growth 403, 3 (2014).

${ }^{17}$ E. Kioupakis, P. Rinke, A. Schleife, F. Bechstedt, and C.G. Van de Walle, Phys. Rev. B 81, $241201(2010)$.

${ }^{18}$ E. Kioupakis, P. Rinke, and C.G. Van de Walle, Appl. Phys. Express 3, 082101 (2010).

${ }^{19}$ G. Yu, G. Wang, H. Ishikawa, M. Umeno, T. Soga, T. Egawa, J. Watanabe, and T. Jimbo, Appl. Phys. Lett. 70, 3209 (1997).

${ }^{20}$ N.A. Sanford, L.H. Robins, A.V. Davydov, A. Shapiro, D.V. Tsvetkov, A.V. Dmitriev, S. Keller, U.K. Mishra, and S.P. DenBaars, J. Appl. Phys. 94, 2980 (2003).

${ }^{21}$ C.G. Van de Walle, Phys. Rev. B 56, R10020 (1997). 
${ }^{22}$ A.F. Wright, J. Appl. Phys. 90, 1164 (2001).

${ }^{23}$ M.P. D'Evelyn, H.C. Hong, D.-S. Park, H. LU, E. Kaminsky, R.R. Melkote, P. Perlin, M. Lesczynski, S. Porowski, and R.J. Molnar, J. Cryst. Growth 300, 11 (2007).

${ }^{24}$ F. Tuomisto, T. Kuittinen, M. Zając, R.M. Doradziński, and D. Wasik, J. Cryst. Growth 403, 114 (2014).

${ }^{25}$ B-C. Chung and M. Gershenzon, J. Appl. Phys., 72, 651, (1992).

${ }^{26}$ A. Hierro, S.A. Ringel, M. Hansen, J.S. Speck, U.K. Mishra, and S.P. DenBaars, Appl. Phys. Lett. 77, 1499 (2000).

${ }^{27}$ Y.S. Puzyrev, T. Roy, M. Beck, B.R. Tuttle, R.D. Schrimpf, D.M. Fleetwood, and S.T. Pantelides, J. Appl. Phys. 109, 034501 (2011). 
Summary of various crystal quality metrics for investigated samples grown using different growth techniques. The Na-Flux and ammonothermal GaN crystals were unintentionally doped with oxygen, whereas HVPE GaN was intentionally doped with oxygen. All other impurities are unintentional.

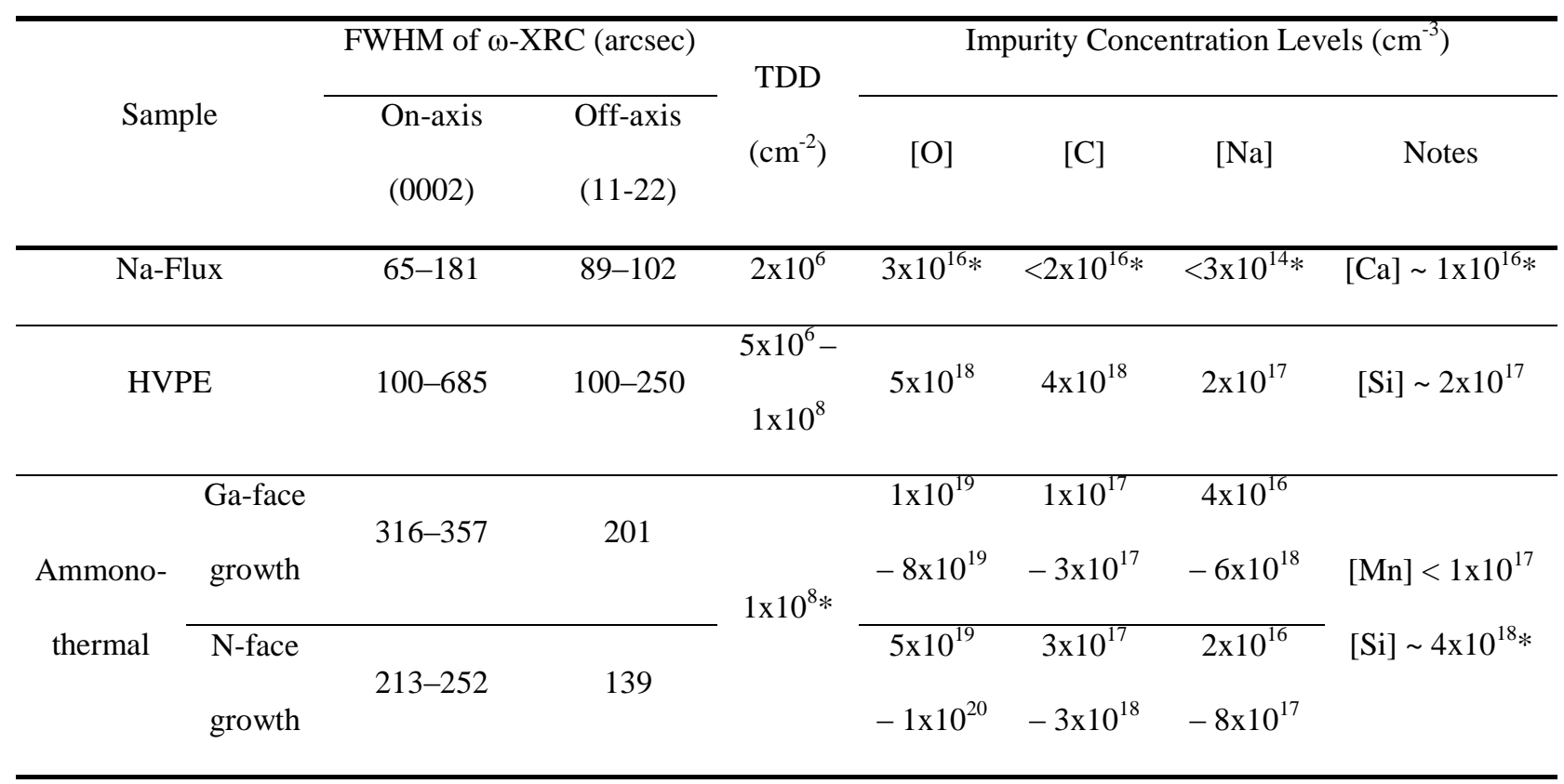

Notes: * indicates typical values, not explicitly evaluated for sample under investigation. Impurities: Na-flux values from Ref [14], ammonothermal GaN from Ref [9], only one HVPE sample was analyzed. TDD for ammonothermal GaN based on HVPE seed TDD density. 
FIG. 1. Hall mobility as a function of free electron concentrations measured at RT for all eight samples part of this study. Growth technique used to grow each respective bulk GaN sample is indicated by its symbol. Comparison is made to two models: Monte Carlo low-field simulations (Ref 12) and a representative fit through numerous experimentally determined mobility data (Ref 13)

FIG. 2. GaN band structure with overlaid possible absorption mechanisms for electrons and holes: (a) dipole forbidden direct absorption from the conduction band minimum to the second conduction band, phonon-assisted (b) intraband and (c) interband absorption, (d) direct absorption from defect state. Colors correspond to energy levels to which an electron from the conduction band minimum or a hole from the valence band maximum would be elevated to after absorbing a photon with an energy corresponding to the displayed color.

FIG. 3. Experimentally determined sub-bandgap optical absorption coefficient traces for bulk $\mathrm{GaN}$ samples grown using different growth techniques as a function of free carrier concentration at RT. Sample thickness is indicated in the legend. Dashed lines represent computationally anticipated values for phonon-assisted free carrier absorption based on first-principle calculations (Ref. 17,18). The 'Theory' column in the figure provides electron densities used for each calculated curve for each respective crystal.

FIG. 4. Dependence of the refractive index, $n$, from experimentally determined reflection coefficient, $R$, on wavelength and free carrier concentration at room temperature. The angle of incidence of unpolarized light for reflectance measurements was $12.5^{\circ}$. Comparison to 
measurements performed on thin films over the full spectrum are included as dashed (Ref 19) and dotted (Ref 20) lines.

FIG. 5. Measured reflectance, $R_{\text {meas }}$, for bulk GaN samples as a function of incident light energy highlighting their behavior near the band edge.

FIG. 6. Fourier transform infrared (FTIR) absorbance measurement on as grown Ga-face grown ammonothermal sample (this work) compared to literature data for another ammonothermal GaN sample (Ref 23) and a characteristic hydride vapor phase epitaxy (HVPE) GaN sample. Peaks are in the region of calculated hydrogen vibration frequencies associated with hydrogenated gallium vacancy species: $2986-3650 \mathrm{~cm}^{-1}$ (Ref 22). 


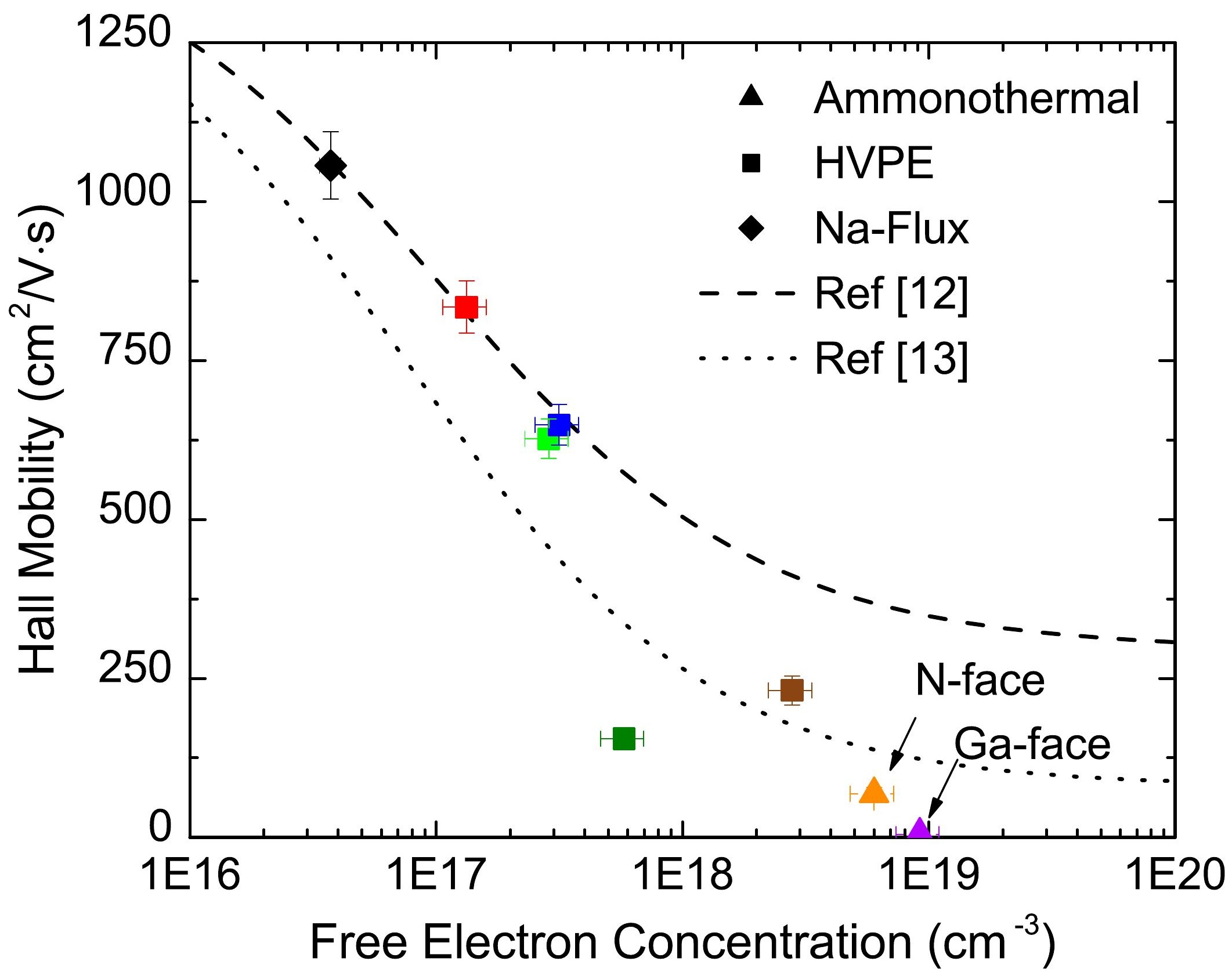


Figure 3

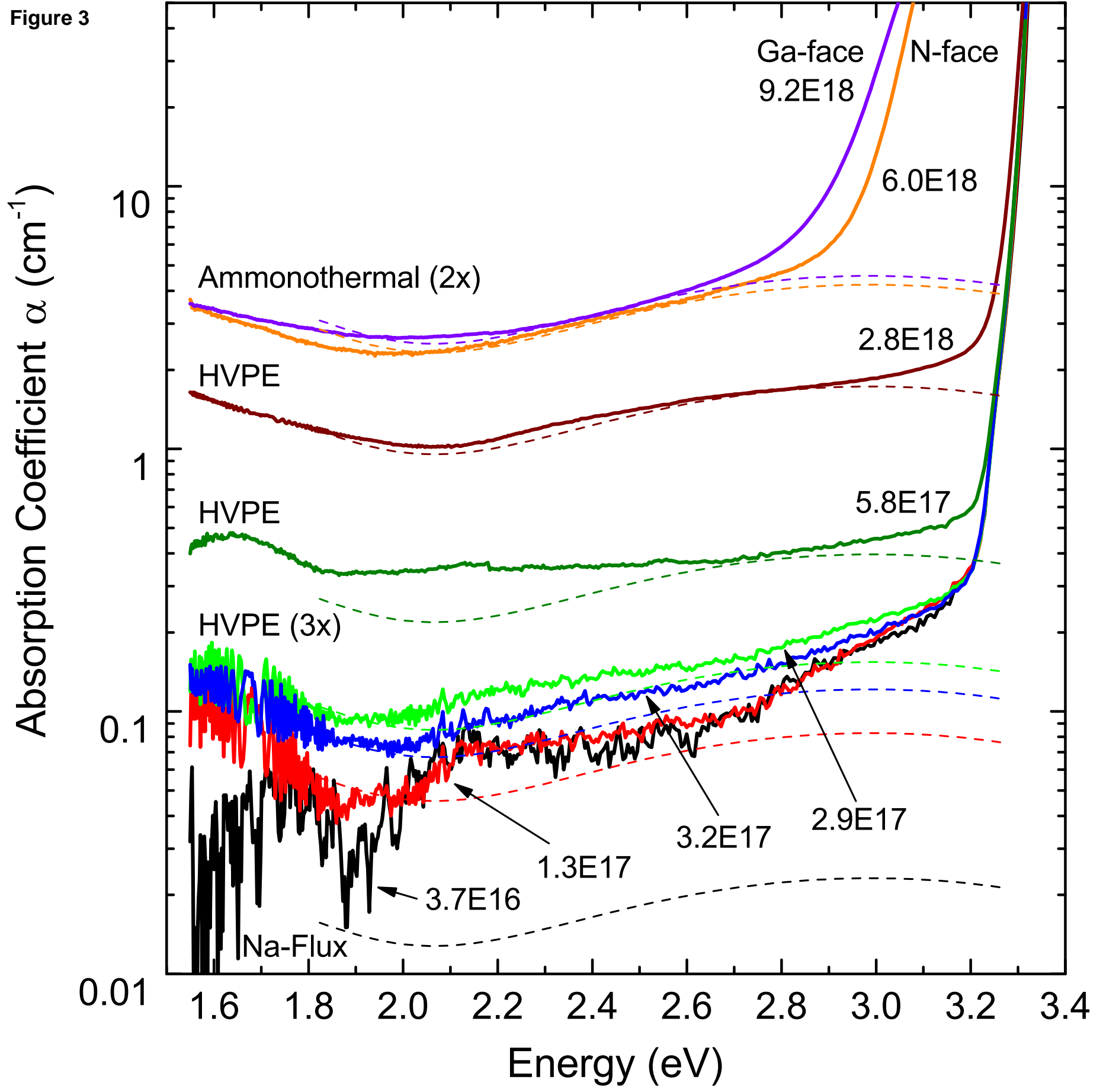

\begin{tabular}{|c|c|c|c|}
\hline \multirow{2}{*}{$\begin{array}{c}\text { Growth } \\
\text { Technique }\end{array}$} & \multicolumn{2}{|c|}{ Free Electron Concentration $\left(\mathbf{c m}^{-3}\right)$} & \multirow{2}{*}{$\begin{array}{c}\text { Thickness } \\
\text { Crystal }(\mu \mathrm{m})\end{array}$} \\
\cline { 2 - 3 } Na-Flux & Experiment & Theory & 490 \\
\hline & $-(3.7 \pm 0.4) \mathrm{E} 16$ & $---3.7 \mathrm{E} 16$ & 334 \\
& $-(1.3 \pm 0.3) \mathrm{E} 17$ & $---1.3 \mathrm{E} 17$ & 337 \\
HVPE & $-(3.2 \pm 0.6) \mathrm{E} 17$ & $----2.0 \mathrm{E} 17$ & 339 \\
& $-(5.8 \pm 1.2) \mathrm{E} 17$ & $---6.4 \mathrm{E} 17$ & 350 \\
& $-(2.8 \pm 0.6) \mathrm{E} 18$ & $----2.8 \mathrm{E} 18$ & 329 \\
\hline Ammono- & $-(6.0 \pm 1.2) \mathrm{E} 18$ & $----6.8 \mathrm{E} 18$ & 630 \\
thermal & $-(9.2 \pm 1.8) \mathrm{E} 18$ & $----7.3 \mathrm{E} 18$ & 636 \\
\hline
\end{tabular}




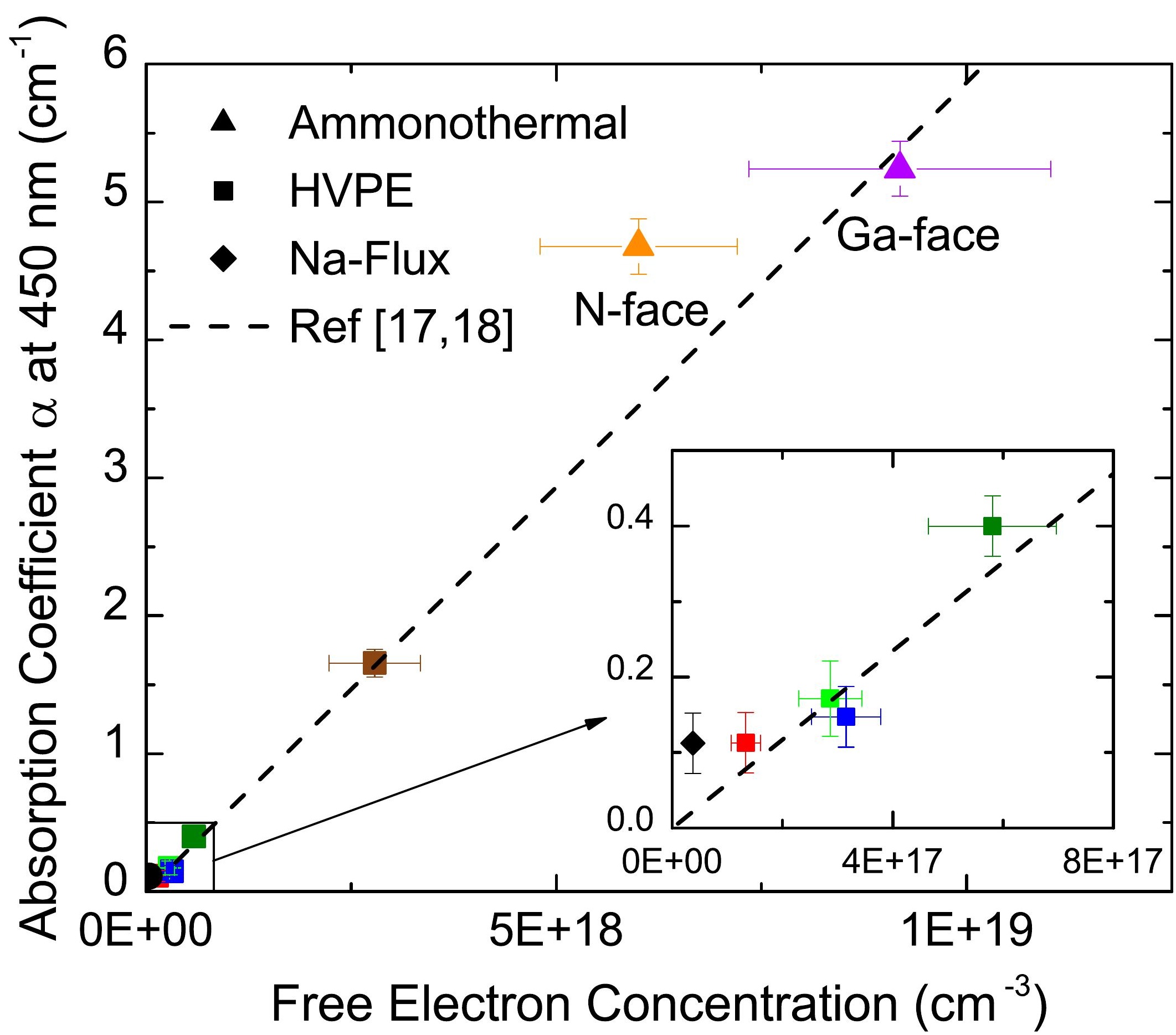




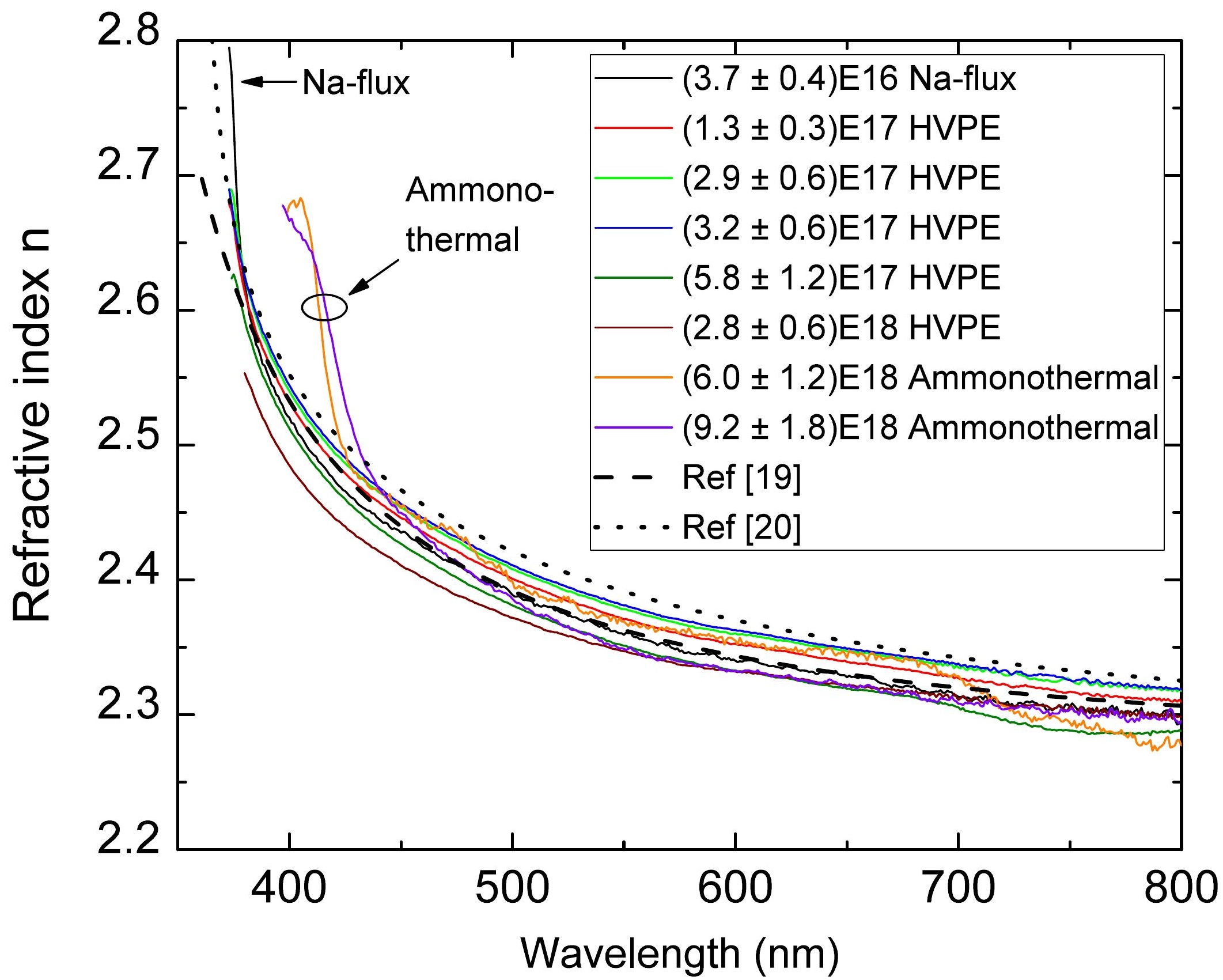




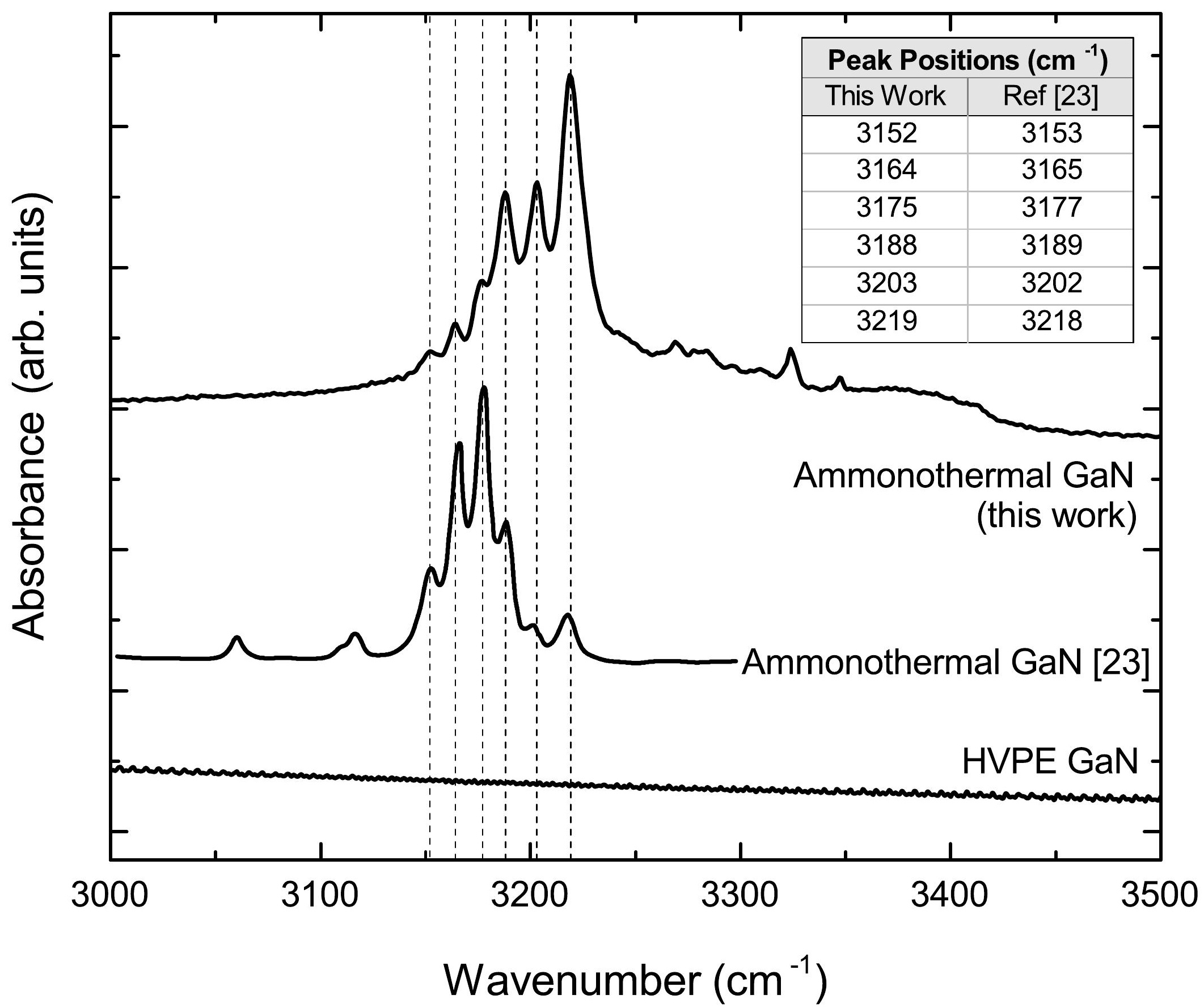

